\title{
Antimicrobial activity of some pyrimidine derivatives in DMF and DMSO
}

\author{
Shipra Baluja ${ }^{1 *}$, Sumitra Chanda ${ }^{2}$ and Kajal Nandha ${ }^{1}$ \\ ${ }^{1}$ Department of Chemistry, ${ }^{2}$ Department of Biosciences, \\ Saurashtra University, Rajkot 360005, Gujarat, India \\ ${ }^{1 *}$ E-mail address: shipra_baluja@rediffmail.com.
}

Keywords: pyrimidine, antibacterial activity, antifungal activity, agar-well diffusion method, N, N,dimethyl formamide, dimethyl sulfoxide

ABSTRACT. A series of pyrimidine derivatives have been synthesized and their structures were confirmed by IR, ${ }^{1} \mathrm{H}$ NMR and mass spectral data. All these synthesized compounds were tested in vitro for their antimicrobial potential against Gram positive, Gram negative strains of bacteria as well as fungal strains in N, N-dimethyl formamide and dimethyl sulfoxide.

\section{INTRODUCTION}

Literature survey shows that a large number of pyrimidine derivatives are reported to exhibit antimycobacterial [1], antitumor [2], antiviral [3], anticancer [4], anti-inflammatory, analgesic, antifolate [5], antimicrobial [6], anti-fungal [7], antiproliferative [8] etc.

In the present work, some novel pyrimidine derivatives were synthesized. The characterization of synthesized compounds was done by IR, NMR and mass spectral analysis.

The antimicrobial activity of the synthesized compounds was done against some pathogenic Gram positive and Gram negative bacteria and fungi in N, N-dimethyl formamide and dimethyl sulfoxide.

\section{EXPERIMENTAL}

\section{Synthesis:}

\section{Synthesis of Int-I (2-(benzo/d]thiazol-2-yl) acetonitrile):}

To the ethanolic solution of 2 -amino thiophenol $(0.1 \mathrm{~mol})$, malono nitrile $(0.1 \mathrm{~mol})$ was added at $0-5{ }^{0} \mathrm{C}$ temperature, and glacial acetic acid was added drop wise. By the removal of ammonia gas, cyclized product was formed (Int-I). The completion of reaction was confirmed by analytical thin layer chromatography (TLC) using (0.75:0.25 Hexane : Ethyl acetate) as mobile phase. The resulting product was filtered, washed with hexane and dried under vacuum. This product was used further in next step.

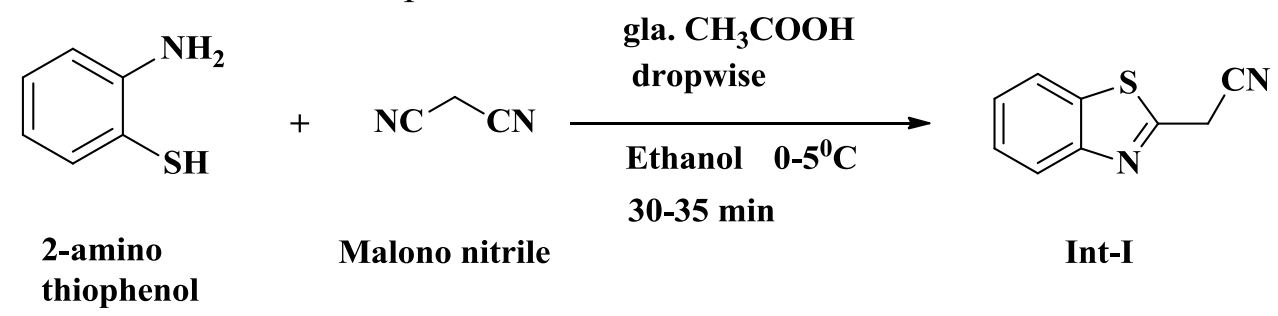

\section{Synthesis of pyrimidines:}

In DMF solution of above synthesized product (Int-I), different substituted aldehydes and guanidine hydrochloride were added. The reaction mixture was refluxed for 8-10 hrs at $145-150{ }^{\circ} \mathrm{C}$ using piperidine as catalysis.. The complecation of reaction was confirmed by analytical thin layer chromatography (TLC) using (ethyl acetate) as mobile phase. After complication of reaction, the reaction mixure was washed with diethyl ether in order to remove non polar impurities. The resulting solid was filtered. 


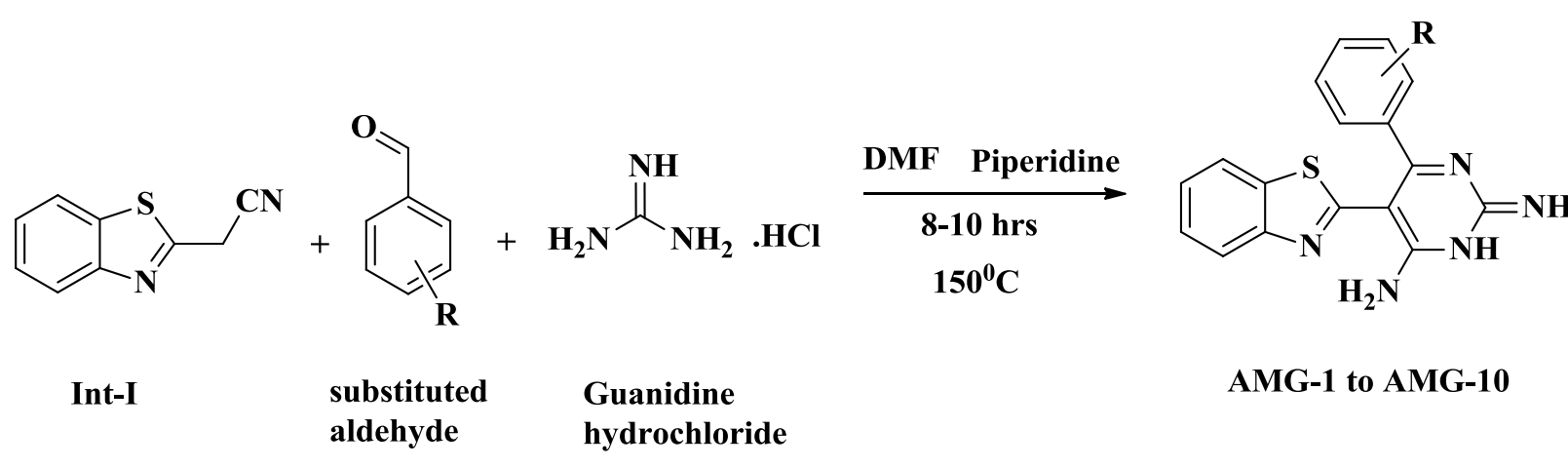

The physical constants of synthesized compounds are shown in Table 1.

The structure confirmation of these crystallized compounds was done by FTIR, ${ }^{1} \mathrm{H}$ NMR and mss spectral data. IR spectra were recorded on IR affinity 1S (furrier transport infra-red spectroscopy), ${ }^{1} \mathrm{H}-\mathrm{NMR}$ spectra were taken on a Bruker AVANCE II 400. In all the cases, ${ }^{1} \mathrm{H}$ NMR spectra were obtained in DMSO- $\mathrm{d}_{6}$ using TMS as an internal standard. The NMR signals are reported in $\delta$ ppm. Mass spectra were determined using direct inlet probe on a GCMS-QP-2010 mass spectrometer.

\section{ANTIMICROBIAL ACTIVITY}

\section{Microorganisms tested:}

The studied microorganisms were obtained from National Chemical Laboratory (NCL), Pune, India. The microorganisms were maintained at $4^{\circ} \mathrm{C}$. The Gram positive bacteria studied were Bacilluscereus ATCC11778 (BC); Staphylococcusaureus ATCC29737 (SA), Corynebacteriumrubrum ATCC14898 (CR), Listeria monocytogenes ATCC19112 (LM), Gram negative bacteria were Escherichia coli NCIM2931 (EC), Pseudomonas aeruginosa ATCC27853(PA), Salmonella typhimurium ATCC23564 (ST), Klebsiellapneumoniae NCIM2719 (KP) and fungal strains were Candida glabrata NCIM3448 (CG), Candida epicola NCIM3367 (CE), Candida albicans ATCC2091 (CA) and Cryptococcusneoformans NCIM3542 (CN). The microorganisms studied are clinically important ones causing several infections and food spoilage. In vitro antimicrobial activity of the pyrimidine was studied against pathogenic microbial strains by the agar well diffusion method [9].

\section{Preparation of solutions of compounds:}

For all the compounds, DMF and DMSO were used for screening of antimicrobial activity. The solution of $20 \mathrm{mg} / \mathrm{ml}$ concentration was prepared for all the compounds.

\section{RESULTS AND DISCUSSION:}

In total, 10 compounds (AMG-1 to AMG-10) were synthesized. Table 1 shows the physical parameters of these compounds. The IR, ${ }^{1} \mathrm{H}$ NMR and mass spectra of compound AMG-2 are shown in Figures 1, 2 and 3 respectively.

\section{Spectral data:}

AMG-1: IR (cm $\left.{ }^{-1}, \mathbf{K B r}\right): 3547.39$ (-NH (pri.) str.), 3099.57 (Ar-H str.), 2938.74 (-CH 2 sym. str.), 1623.14 (-NH bending vib. Secondary amine), 1358.62 (-CH bending.), 1347.56 (C-N (sec) bending), 1242-1010 (C-H in plane bending, phenyl ring), 752.34 (C-H str. 5-adjecent c atoms), 730.52 (C-Cl str.), ${ }^{1} \boldsymbol{H}$ NMR (DMSO-d $)$ $\boldsymbol{\delta}$ (ppm) : 5.136 (2H, singlet, $\left.-\mathrm{NH}_{2}\right)$, 7.287-7.314 (2H, -CH, multiplet), $7.024(1 \mathrm{H}$, singlet, $-\mathrm{NH}), 7.264-7.428(4 \mathrm{H}$, multiplet, $-\mathrm{CH}), 7.535-7.610(1 \mathrm{H}$, multiplet, -NH), 7.630-7.650 (1H, doublet, $-\mathrm{CH}), 7.904-7.925(1 \mathrm{H}$, doublet, $-\mathrm{CH}), \mathbf{M S}:(\boldsymbol{m} / \mathbf{z})=353$ 
AMG-2: IR (cm $\left.{ }^{-1}, \boldsymbol{K B r}\right): 3517.26$ (-NH (sec.) str.), 3026.39 (Ar-H str.), 2914.47 (-CH2 sym. str.), 2969.63 (- $\mathrm{CH}_{2}$ sym. str.), 2896.35 (C-H Str. (alkane), 1627.28 (-NH bending vib. Secondary amine), 1347.69 (-CH bending.), 1369.24 (C-N (sec) bending.), 1242-1010 (C-H in plane bending, phenyl ring), 751.38 (C-H str. 5-adjecent c atoms), ${ }^{1} \boldsymbol{H} \mathbf{N M R}\left(\boldsymbol{D M S O}-\boldsymbol{d}_{\boldsymbol{\sigma}}\right) \boldsymbol{\delta}(\mathbf{p p m}): 3.827$ (3H, singlet, $\left.-\mathrm{OCH}_{3}\right), 3.939\left(3 \mathrm{H}\right.$, singlet- $\left.\mathrm{OCH}_{3}\right), 5.072\left(2 \mathrm{H}\right.$, singlet, $\left.-\mathrm{NH}_{2}\right), 6.890-7.925(2 \mathrm{H},-\mathrm{CH}$, multiplet), $7.024(1 \mathrm{H}$, singlet, -NH), 7.264-7.428 (4H, multiplet, $-\mathrm{CH}), 7.630-7.650(1 \mathrm{H}$, doublet, $\mathrm{CH}), 7.904-7.925(1 \mathrm{H}$, doublet, $-\mathrm{CH}), \boldsymbol{M S}:(\boldsymbol{m} / \mathbf{z})=379$

AMG-3: IR (cm $\left.{ }^{-1}, \mathbf{K B r}\right): 3471.87$ (-NH (pri.) str.), 3161.33 (Ar-H str.), 3007.14 (-CH $\mathrm{CH}_{2}$ sym. str.), 2227.86 (-CN str.), 1664.62( $\mathrm{C}=\mathrm{C}$ str. $\alpha, \beta$ unsaturated 6-member ring), 1604.83(-NH bending vib. Secondary amine), 1381.08 (-CH bending.), 1315.50(C-N (sec) bending.), 1242-1010(C-H in plane bending, phenyl ring), 767.69 (C-H str. 5-adjecent c atoms), 767.69(C-Cl str.), ${ }^{1} \boldsymbol{H}$ NMR (DMSO$\left.\boldsymbol{d}_{\boldsymbol{6}}\right) \boldsymbol{\delta}(\mathbf{p p m}): 6.789\left(2 \mathrm{H}\right.$, singlet, $\left.-\mathrm{NH}_{2}\right), 7.287-7.314(2 \mathrm{H},-\mathrm{CH}$, multiplet $), 7.264-7.428(4 \mathrm{H}$, multiplet, -CH), 7.440-7.493 (1H, multiplet, -NH), 7.862-7.921 (1H, doublet, -CH), 7.970-8.021 $(1 \mathrm{H}$, doublet, $-\mathrm{CH}) 8.499(1 \mathrm{H}$, broad, $-\mathrm{NH}), \boldsymbol{M S}:(\boldsymbol{m} / \mathbf{z})=353$

AMG-4: IR (cm $\left.{ }^{-1}, \mathbf{K B r}\right): 3474.27$ (-NH (pri.) str.), 3199.68 (Ar-H str.), 2970.38 (-CH $\mathrm{CH}_{2}$ sym. str.), 1602.85 (-NH bending vib. primary amine), 1365.60 (-CH bending.), 1242-1010 (C-H in plane bending, phenyl ring), 721.38 (C-H str. 5-adjecent c atoms), 651.94 (C-Br str.), ${ }^{1} \boldsymbol{H}$ NMR (DMSO$\boldsymbol{d}_{\text {6) }} \boldsymbol{\delta}$ (ppm) : 6.028 (2H, singlet, $\left.-\mathrm{NH}_{2}\right), 7.189-7.204$ (2H, -CH, multiplet), 7.324 (1H, singlet, $\left.-\mathrm{NH}\right)$, 7.458-7.624 (4H, multiplet, -CH), 7.815-7.898 (1H, doublet, $-\mathrm{CH}), 8.014-8.147(1 \mathrm{H}$, doublet, $-\mathrm{CH})$, 8.106-8.247 (1H, broad, -NH), MS: $(\boldsymbol{m} / \mathbf{z})=398$

AMG-5: IR (cm $\left.{ }^{-1}, \mathbf{K B r}\right): 3649.32$ (-NH (pri.) str.), 3012.57 (Ar-H str.), 2954.95 (-CH2 sym. str.), 2912.57 (C-H Str. (alkane), 1606.70 (-NH bending vib. primary amine), 1431.18 (-CH bending (alkane)), 1365.60 (-CH bending.), 1242-1010 (C-H in plane bending, phenyl ring), 729.09 (C-H str. 5-adjecent c atoms), ${ }^{1} \boldsymbol{H}$ NMR (DMSO-d $)$ ס(ppm) : $3.639\left(3 \mathrm{H}\right.$, singlet, $\left.-\mathrm{OCH}_{3}\right), 6.675(2 \mathrm{H}$, singlet, $\left.-\mathrm{NH}_{2}\right), 6.962-6.996(2 \mathrm{H}$, multiplet $-\mathrm{CH}),, 7.024(1 \mathrm{H}$, multiplet, $-\mathrm{NH}), 7.180-7.602(4 \mathrm{H}$, multiplet, $-\mathrm{CH}), 7.360-7.452(1 \mathrm{H}$, doublet, $-\mathrm{CH}), 7.631-7.784(1 \mathrm{H}$, doublet, $-\mathrm{CH}), 7.968(1 \mathrm{H}$, broad, -NH), $\boldsymbol{M S}:(\boldsymbol{m} / \mathbf{z})=349$

AMG-6: IR (cm $\left.{ }^{-1}, \mathbf{K B r}\right): 3612.57$ (-NH (pri.) str.), 3147.28 (Ar-H str.), 2970.41 (-CH $\mathrm{CH}_{2}$ sym. str.), 1645.28 (-NH bending vib. primary amine), 1365.60 (-CH bending.), 1242-1010 (C-H in plane bending, phenyl ring), 721.38 (C-H str. 5-adjecent c atoms), 1091.71 (C-F str.), ${ }^{1} \boldsymbol{H}$ NMR (DMSOd $\boldsymbol{d}_{\boldsymbol{6}} \boldsymbol{\delta}$ (ppm) : $6.743\left(2 \mathrm{H}\right.$, singlet, $\left.-\mathrm{NH}_{2}\right), 6.904-6.948(2 \mathrm{H},-\mathrm{CH}$, multiplet $), 7.000(1 \mathrm{H}$, multiplet, $\mathrm{NH})$, 7.258-7.501 (4H, multiplet, $-\mathrm{CH}), 7.835-7.943(1 \mathrm{H}$, doublet, $-\mathrm{CH}), 7.963-8.062(1 \mathrm{H}$, doublet, $-\mathrm{CH}), 8.259-8.612(1 \mathrm{H}$, multiplet, $-\mathrm{NH}), \boldsymbol{M S}:(\boldsymbol{m} / \mathbf{z})=337$

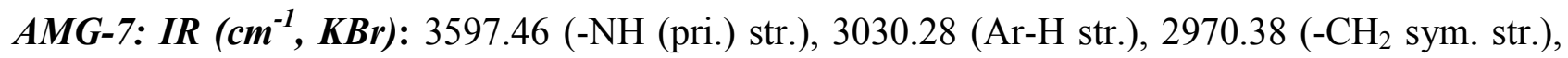
2914.75 (C-H Str. (alkane), 1614.73 (-NH bending vib. primary amine), 1435.04 (-CH bending (alkane)), 1365.60 (-CH bending.), 1242-1010 (C-H in plane bending, phenyl ring), 727.16 (C-H str. 5-adjecent c atoms), ${ }^{1} \boldsymbol{H}$ NMR (DMSO-d $)$ d(ppm) : $3.512\left(3 \mathrm{H}\right.$, singlet, $\left.-\mathrm{CH}_{3}\right), 6.145$ (2H, singlet, $\left.-\mathrm{NH}_{2}\right), 6.358-6.476(2 \mathrm{H}$, multiplet $-\mathrm{CH}),, 6.742(1 \mathrm{H}$, multiplet, $-\mathrm{NH}), 6.823-7.015(4 \mathrm{H}$, multiplet, $-\mathrm{CH}), 7.263-7.324(1 \mathrm{H}$, doublet, $-\mathrm{CH}), 7.534-7.627(1 \mathrm{H}$, doublet, $-\mathrm{CH}), 8.017(1 \mathrm{H}$, broad, -NH), MS: $(\boldsymbol{m} / \mathbf{z})=333$

AMG-8: IR (cm $\left.{ }^{-1}, \mathbf{K B r}\right): 3481.51$ (-NH (pri.) str.), 3151.69 (Ar-H str.), 2970.38 (-CH $\mathrm{CH}_{2}$ sym. str.), 2890.24 (C-H Str. (alkane), 1587.42 (-NH bending vib. primary amine), 1435.04 (-CH bending (alkane)), 1365.60 (-CH bending.), 1242-1010 (C-H in plane bending, phenyl ring), 729.09 (C-H str. 5-adjecent c atoms), ${ }^{1} \boldsymbol{H}$ NMR (DMSO-d $)$ ס(ppm) : $3.721\left(3 \mathrm{H}\right.$, singlet, $\left.-\mathrm{OCH}_{3}\right), 6.748(2 \mathrm{H}$, singlet, $\left.-\mathrm{NH}_{2}\right), 6.962-6.996(2 \mathrm{H}$, multiplet $-\mathrm{CH}),, 7.024(1 \mathrm{H}$, multiplet, $-\mathrm{NH}), 7.180-7.602(4 \mathrm{H}$, 
multiplet, $-\mathrm{CH}), 7.813-7.832(1 \mathrm{H}$, doublet, $-\mathrm{CH}), 7.943-7.962(1 \mathrm{H}$, doublet, $-\mathrm{CH}), 8.439(1 \mathrm{H}$, broad, -NH), $\boldsymbol{M S}:(\boldsymbol{m} / \mathbf{z})=349$

AMG-9: IR (cm $\left.{ }^{-1}, \mathbf{K B r}\right): 3514.27$ (-NH (pri.) str.), 3215.36 (Ar-H str.), 2970.41 (-CH $\mathrm{CH}_{2}$ sym. str.), 1602.57 (-NH bending vib. primary amine), 1365.60 (-CH bending.), 1242-1010 (C-H in plane bending, phenyl ring), 704.02 (C-H str. 5-adjecent c atoms), ${ }^{1} \boldsymbol{H}$ NMR (DMSO-d ( $_{\text {) }} \boldsymbol{\delta}$ (ppm) : 6.028 (2H, singlet, $\left.-\mathrm{NH}_{2}\right), 6.745-6.821(2 \mathrm{H}$, $-\mathrm{CH}$, multiplet), $7.247(1 \mathrm{H}$, singlet, $-\mathrm{NH}), 7.432-7.536(3 \mathrm{H}$, multiplet, $-\mathrm{CH}), 7.639-7.782(1 \mathrm{H}$, doublet, $-\mathrm{CH}), 7.839-7.904(1 \mathrm{H}$, doublet, $-\mathrm{CH}), 8.439(1 \mathrm{H}$, broad, -NH), $\boldsymbol{M S}:(\boldsymbol{m} / \mathbf{z})=325$

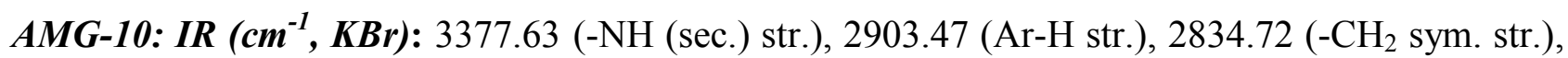
1596.21 (-NH bending vib. Secondary amine), 1346.35 (-CH bending.), 1302.39 (C-N (sec) bending.), 1242-1010 (C-H in plane bending, phenyl ring), 725.63 (C-H str. 5-adjecent c atoms), ${ }^{1} \boldsymbol{H}$ NMR (DMSO-d $\boldsymbol{d}_{\boldsymbol{6}} \boldsymbol{\delta}(\boldsymbol{p p m}): 3.523\left(3 \mathrm{H}\right.$, singlet, $\left.-\mathrm{OCH}_{3}\right), 3.963\left(3 \mathrm{H}\right.$, singlet-OCH $\left.{ }_{3}\right), 6.254(2 \mathrm{H}$, singlet, $\left.-\mathrm{NH}_{2}\right), 6.635-6.702(2 \mathrm{H}$, multiplet, $-\mathrm{CH}),, 7.114(1 \mathrm{H}$, multiplet, $-\mathrm{NH}), 7.632-7.728(3 \mathrm{H}$, multiplet, $-\mathrm{CH}), 7.830-7.912(1 \mathrm{H}$, doublet, $-\mathrm{CH}), 7.934-7.996(1 \mathrm{H}$, doublet, $-\mathrm{CH}), 8.012-8.236(1 \mathrm{H}$, broad, $-\mathrm{NH}), \boldsymbol{M S}:(\boldsymbol{m} / \mathbf{z})=379$

\section{Antibacterial activity:}

Figure 4 shows the zone of inhibition of synthesized compound against Gram positive bacteria in DMF and DMSO. In DMF (Figure 4[A]), against BC AMG-5 exhibited maximum inhibition and minimum is shown by AMG-4. The compounds AMG-1, AMG-6 and AMG-8 showed moderate inhibition against BC. Other compounds had no effect at all. In DMSO, against BC, AMG-1 had maximum inhibition whereas minimum inhibition is due to AMG-6. Some of the compounds had no effect all against BC. The results suggest that inhibition depends not only on structure of compounds but also on the solvent. Against BC, in DMF, maximum compounds had inhibition as compared to DMSO. So, for this strain, DMF is more effective. The comparison of inhibition among different compounds shows that all the compounds have the same central moiety but different substitution groups. In DMF, AMG-5 containing 4-methoxy group showed maximum inhibition against $\mathrm{BC}$. The compound AMG- 8 also contains methoxy group but at $3^{\text {rd }}$ position but its effect is less as compared to AMG-5. This suggests that position of group also affect inhibition. In DMSO, against BC AMG-1 containing 4-chloro group had maximum effect but when chloro group is at $3^{\text {rd }}$ position as in AMG-3, it had no effect at all.

Against SA, AMG-6 exhibited maximum inhibition in DMF whereas AMG-3 had minimum inhibition. Other compounds showed moderate inhibition except AMG-5 and AMG-8. Thus, in DMF against this strain 4-fluoro group is very effective whereas methoxy group at $3^{\text {rd }}$ and $4^{\text {th }}$ position had no effect at all. However, in DMSO against SA, only AMG-1, AMG-5, AMG-6 and AMG-9 showed inhibition and maximum is exhibited by AMG-6 containing 4-fluoro group. The comparison of inhibition against this strain in the two solvents again suggests DMF to be good solvent.

AMG-1, AMG-5, AMG-6, AMG-8, and AMG-9 could inhibit CR in DMF and effect is maximum for AMG-1 containing 4-chloro group. In DMSO, only AMG-5 containing 4-methoxy and AMG-9 containing thiophene inhibit CR.

For LM, not a single compound was effective in DMF whereas in DMSO, only AMG-5 exhibited inhibition.

All over, AMG-6 (containing 4-flouro group) could inhibit $75 \%$ of Gram positive bacteria in DMF solvent and AMG-5 could inhibit $100 \%$ the zone of inhibition in DMSO solvent. Thus overall, AMG-5 having 4-OCH 3 substitution is more effective for studied Gram positive bacteria in both the solvents and DMF is good solvent for the studied Gram positive bacteria.

Figure 5 shows zone of inhibition against Gram negative bacteria in DMF and DMSO. Only AMG-2 and AMG-3 containing 3,4-dimethoxy and 3-chloro groups respectively inhibit EC in 
DMF whereas AMG-6 and AMG-8 containing 4-flouro and 3-methoxy groups respectively could inhibit EC in DMSO. Thus, position of group and solvent affect inhibition.

Against PA, only one compound AMG-8 containing 3-methoxy group showed inhibition in DMF whereas in DMSO, AMG-2 and AMG-3 exhibited inhibition. Thus, in DMSO, 3,4-dimethoxy and 3-chloro groups are effective.

In DMF, against ST only AMG-1 and AMG-10 showed inhibition and maximum inhibition is by AMG-1 containing 4-chloro group. AMG-2, AMG-4, AMG-6 and AMG-8 could inhibit ST in DMSO and 3,4-dimethoxy group present in AMG-2 is most effective.

In DMF, AMG-4, AMG-8 and AMG-9 showed inhibition against $\mathrm{KP}$ and maximum inhibition is by AMG-4 containing 4-bromo group. None of the compound could inhibit KP in DMSO.

Thus, among studied Gram negative bacteria, for the studied compounds, DMSO is better solvent and KP is the most resistant bacteria. Further, the studied compounds are found to be not as effective against Gram negative bacteria as compared to Gram positive bacteria.

The zones of inhibition against four fungal strains are shown in Figure 6 for all the compounds in DMF and DMSO. Not a single compound could inhibit CG in both DMF and DMSO. Thus, CG is most resistant fungal strain among the selected fungal strains for the studied compounds.

All the studied compounds show moderate activity against CE in DMF whereas only AMG5 containing 4-methoxy group inhibited $\mathrm{CE}$ in DMSO. So, $-\mathrm{OCH}_{3}$ group at $4^{\text {th }}$ position is more effective for CE in DMSO. Whereas all the groups are effective in DMF.

Except AMG-8 and AMG-9, all the studied compounds showed inhibition against CA in DMF. Whereas only AMG-4 and AMG-5 could inhibit CA in DMF. Against CN, all the compounds except AMG-4, AMG-5 and AMG-10, exhibited inhibition in DMF. However, in DMSO, only AMG-3 and AMG-5 could inhibit.

AMG-5 and AMG-6 having 4-OCH 3 and 4-F substitution respectively. AMG-5 could inhibit $75 \%$ zone of inhibition in both the solvents. AMG- 6 could inhibit $75 \%$ of the studied fungal strains in DMF whereas in DMSO, this compound had no effect at all.

Again, for the studied fungal strains, DMF is better solvent.

\section{CONCLUSION}

It is concluded that inhibition depends on solvent used, molecular structure of compound and bacterial strain. Overall, DMF is better solvent for the studied compounds and compounds containing methoxy group is most effective. Thus, such compound can act as lead molecule for the synthesis of new therapeutic drug.

Table 1: The physical constants of all the synthesized compounds

\begin{tabular}{|c|c|c|c|c|c|c|}
\hline $\begin{array}{l}\text { Compound } \\
\text { Code }\end{array}$ & $\begin{array}{c}\text { Substitution } \\
\boldsymbol{R}\end{array}$ & $\begin{array}{l}\text { Molecular } \\
\text { formula }\end{array}$ & $\begin{array}{c}\text { Molecular } \\
\text { Weight } \\
\text { g/mol }\end{array}$ & Yield (\%) & $\begin{array}{c}R_{f} \\
\text { value }\end{array}$ & $\begin{array}{l}\text { Melting } \\
\text { point }^{\circ} \mathrm{C}\end{array}$ \\
\hline$A M G-1$ & $-4-\mathrm{Cl}$ & $\mathrm{C}_{17} \mathrm{H}_{12} \mathrm{ClN}_{5} \mathrm{~S}$ & 353.05 & 47 & 0.56 & 205 \\
\hline$A M G-2$ & $-3,4-\mathrm{diOCH}_{3}$ & $\mathrm{C}_{19} \mathrm{H}_{17} \mathrm{~N}_{5} \mathrm{O}_{2} \mathrm{~S}$ & 379.11 & 45 & 0.48 & 274 \\
\hline$A M G-3$ & $-3-\mathrm{Cl}$ & $\mathrm{C}_{17} \mathrm{H}_{12} \mathrm{ClN}_{5} \mathrm{~S}$ & 353.05 & 40 & 0.54 & 236 \\
\hline$A M G-4$ & $-4-\mathrm{Br}$ & $\mathrm{C}_{17} \mathrm{H}_{12} \mathrm{BrN}_{5} \mathrm{~S}$ & 398.28 & 42 & 0.53 & 201 \\
\hline$A M G-5$ & $-4-\mathrm{OCH}_{3}$ & $\mathrm{C}_{18} \mathrm{H}_{15} \mathrm{~N}_{5} \mathrm{OS}$ & 349.41 & 44 & 0.51 & 247 \\
\hline$A M G-6$ & $-4-F$ & $\mathrm{C}_{17} \mathrm{H}_{12} \mathrm{FN}_{5} \mathrm{~S}$ & 337.37 & 39 & 0.52 & 194 \\
\hline$A M G-7$ & $-4-\mathrm{CH}_{3}$ & $\mathrm{C}_{18} \mathrm{H}_{15} \mathrm{~N}_{5} \mathrm{~S}$ & 333.41 & 36 & 0.52 & 216 \\
\hline$A M G-8$ & $-3-\mathrm{OCH}_{3}$ & $\mathrm{C}_{18} \mathrm{H}_{15} \mathrm{~N}_{5} \mathrm{OS}$ & 349.41 & 43 & 0.50 & 241 \\
\hline$A M G-9$ & Thiophene & $\mathrm{C}_{15} \mathrm{H}_{11} \mathrm{~N}_{5} \mathrm{~S}_{2}$ & 325.41 & 56 & 0.49 & 213 \\
\hline$A M G-10$ & $2,5-\mathrm{diOCH}_{3}$ & $\mathrm{C}_{19} \mathrm{H}_{17} \mathrm{~N}_{5} \mathrm{O}_{2} \mathrm{~S}$ & 379.44 & 35 & 0.46 & 247 \\
\hline
\end{tabular}




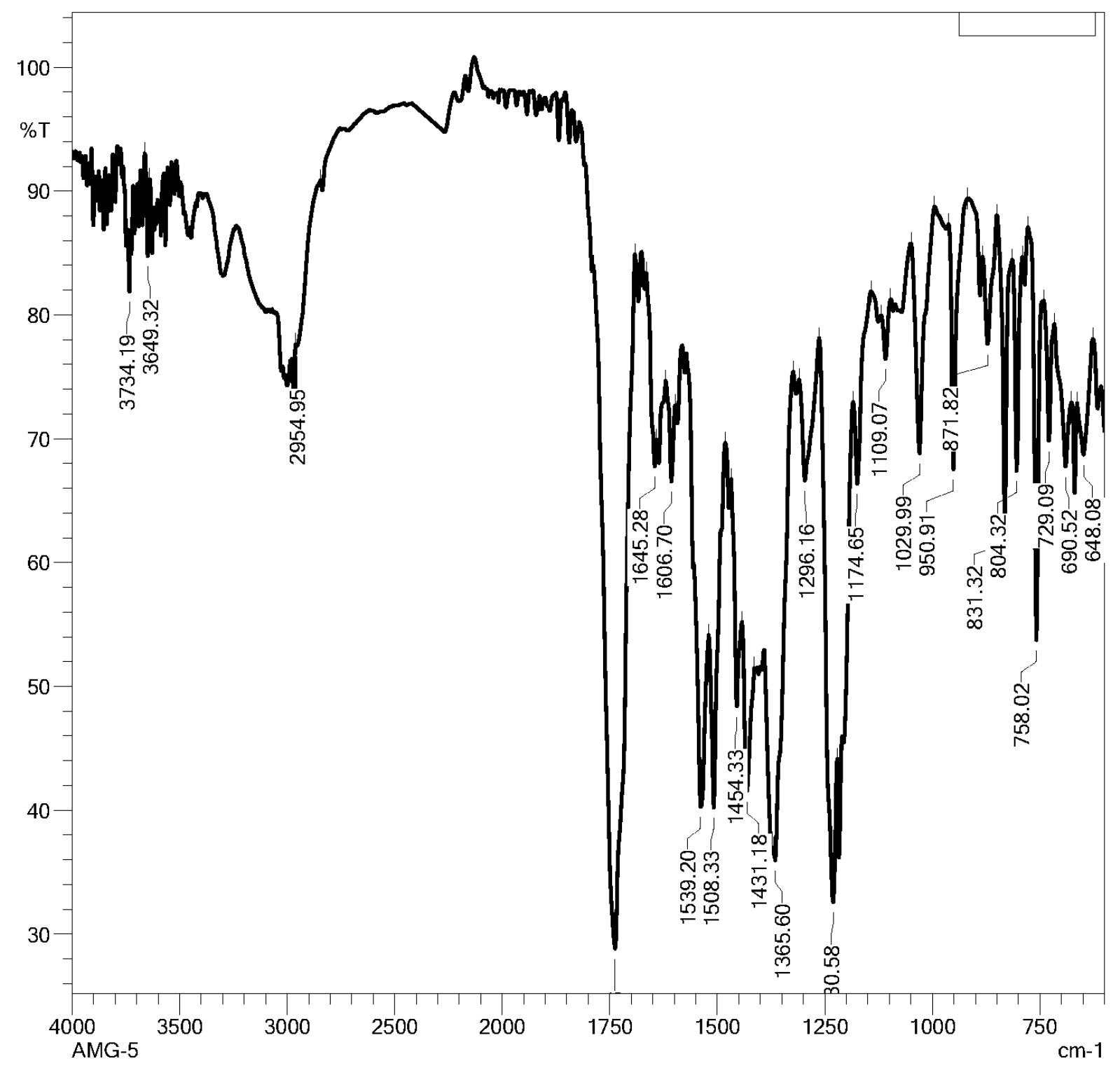

Figure 1: IR spectra of compound AMG-2 


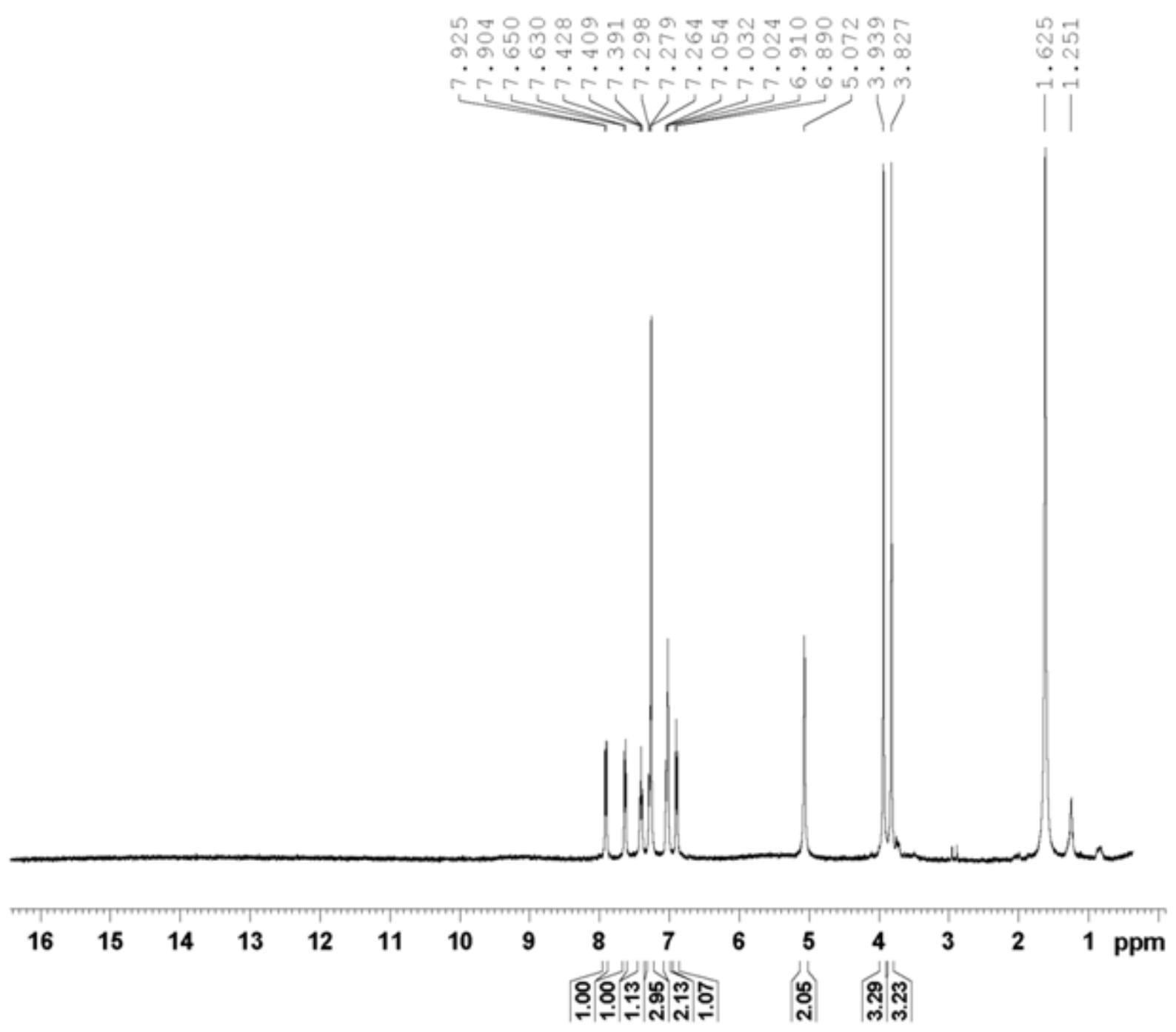

Figure 2: ${ }^{1} \mathrm{H}$ NMR spectra of compound AMG-2.

Line\#:1 R.Time:2.6(Scan\#:258)

MassPeaks: 255

RawMode:Averaged 1.0-8.2(58-919) BasePeak:378.900(1811)

BG Mode:None Group 1 - Event 1

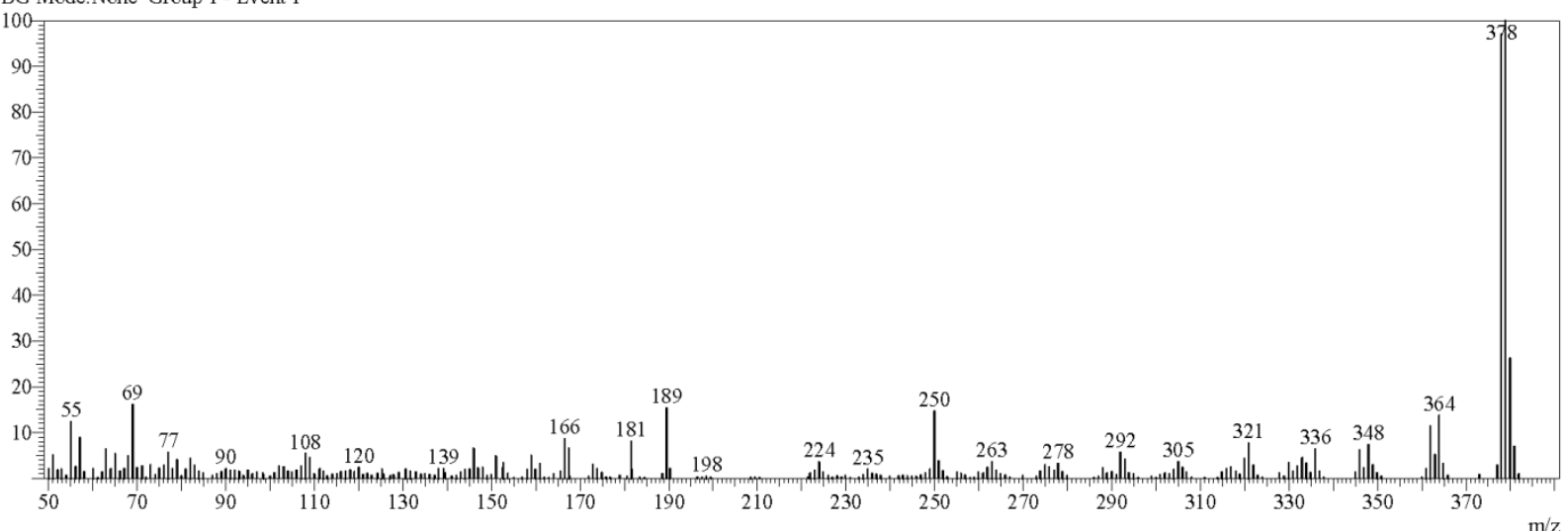

Figure 3: Mass spectra of compound AMG-2. 

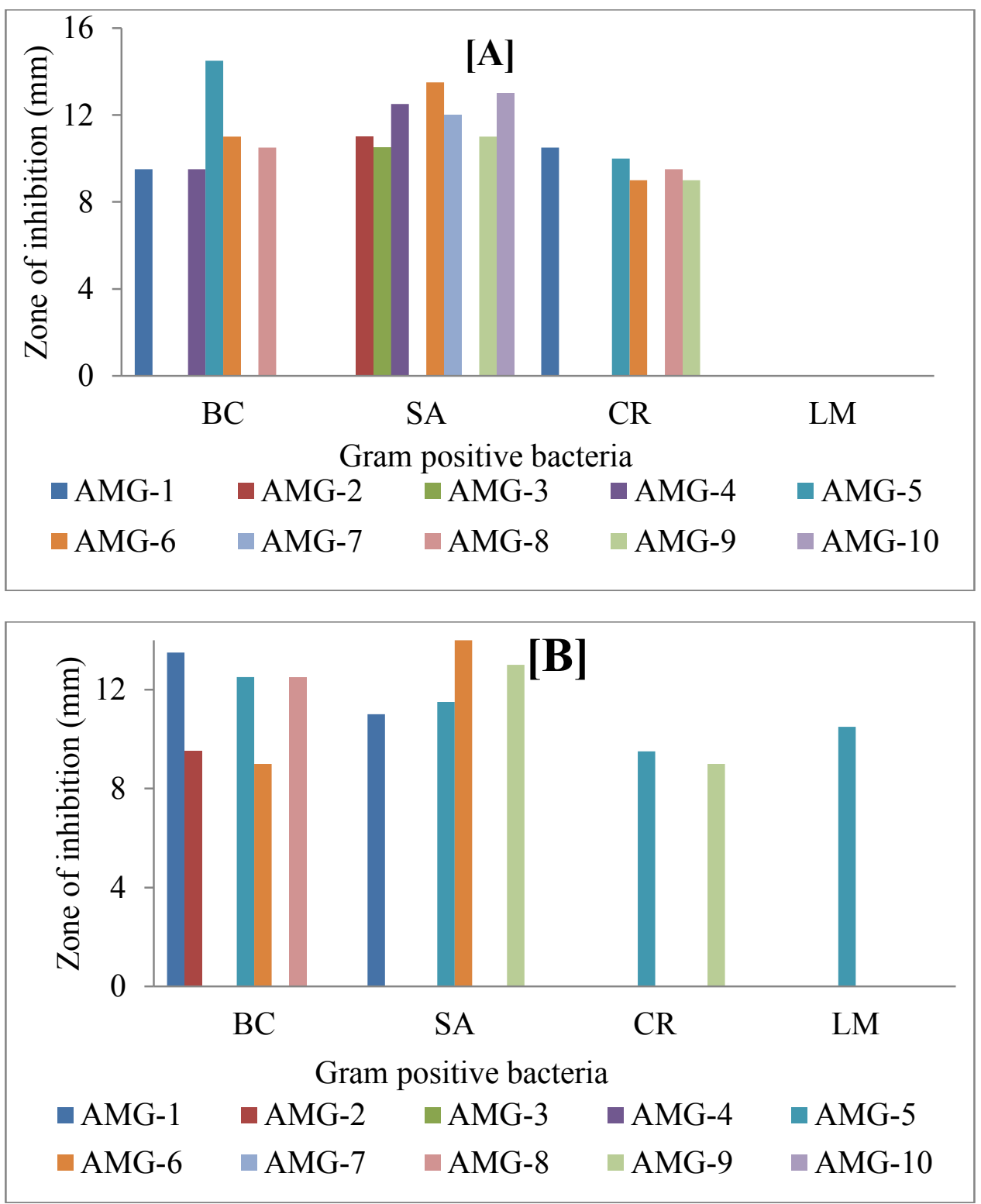

Figure 4: Activity of compounds AMG-1 to AMG-10 against Gram positive bacteria in [A] DMF and [B] DMSO. 

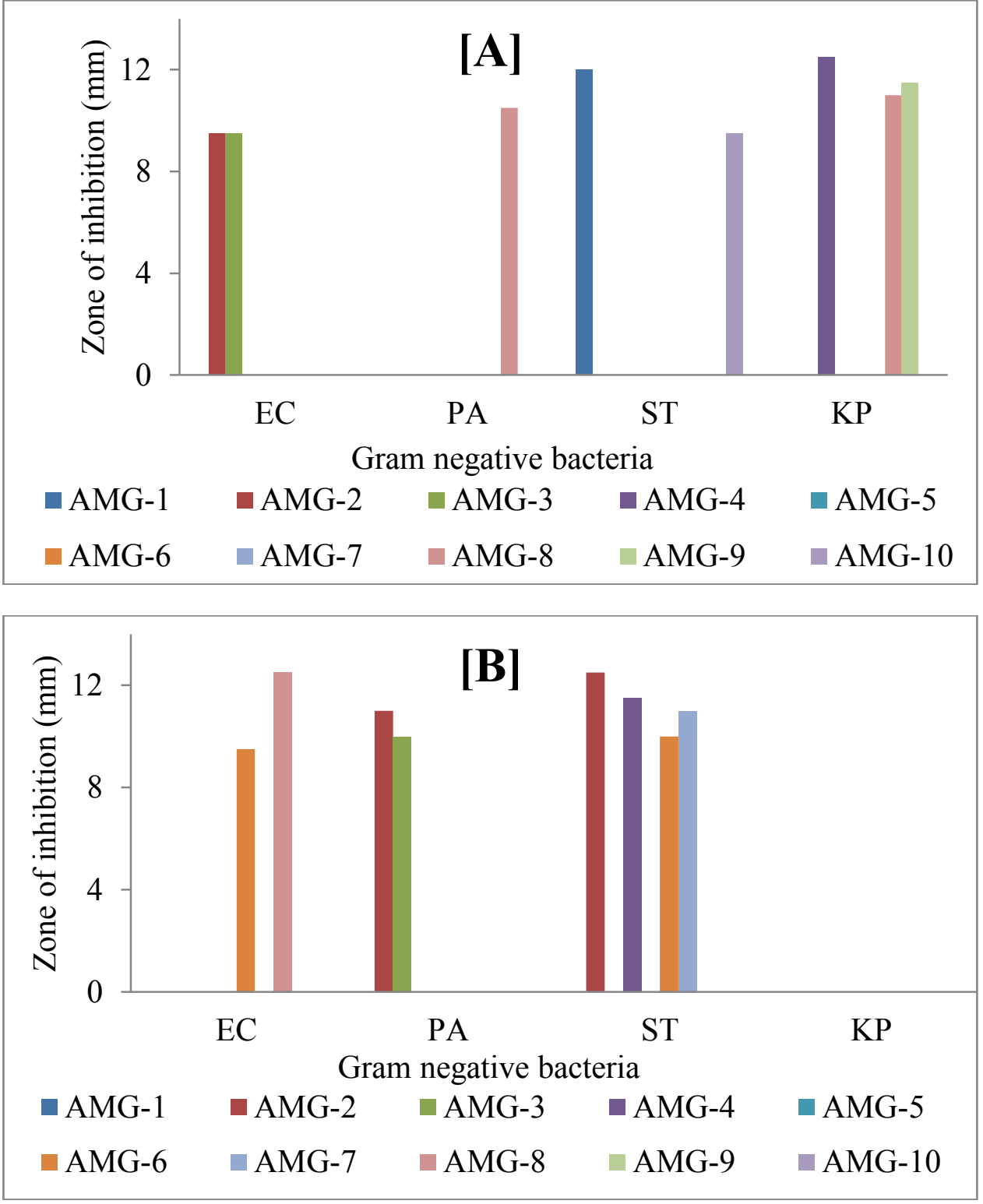

Figure 5: Antimicrobial activity of compounds AMG-1 to AMG-10 against Gram negative bacteria in [A] DMF and [B] DMSO. 

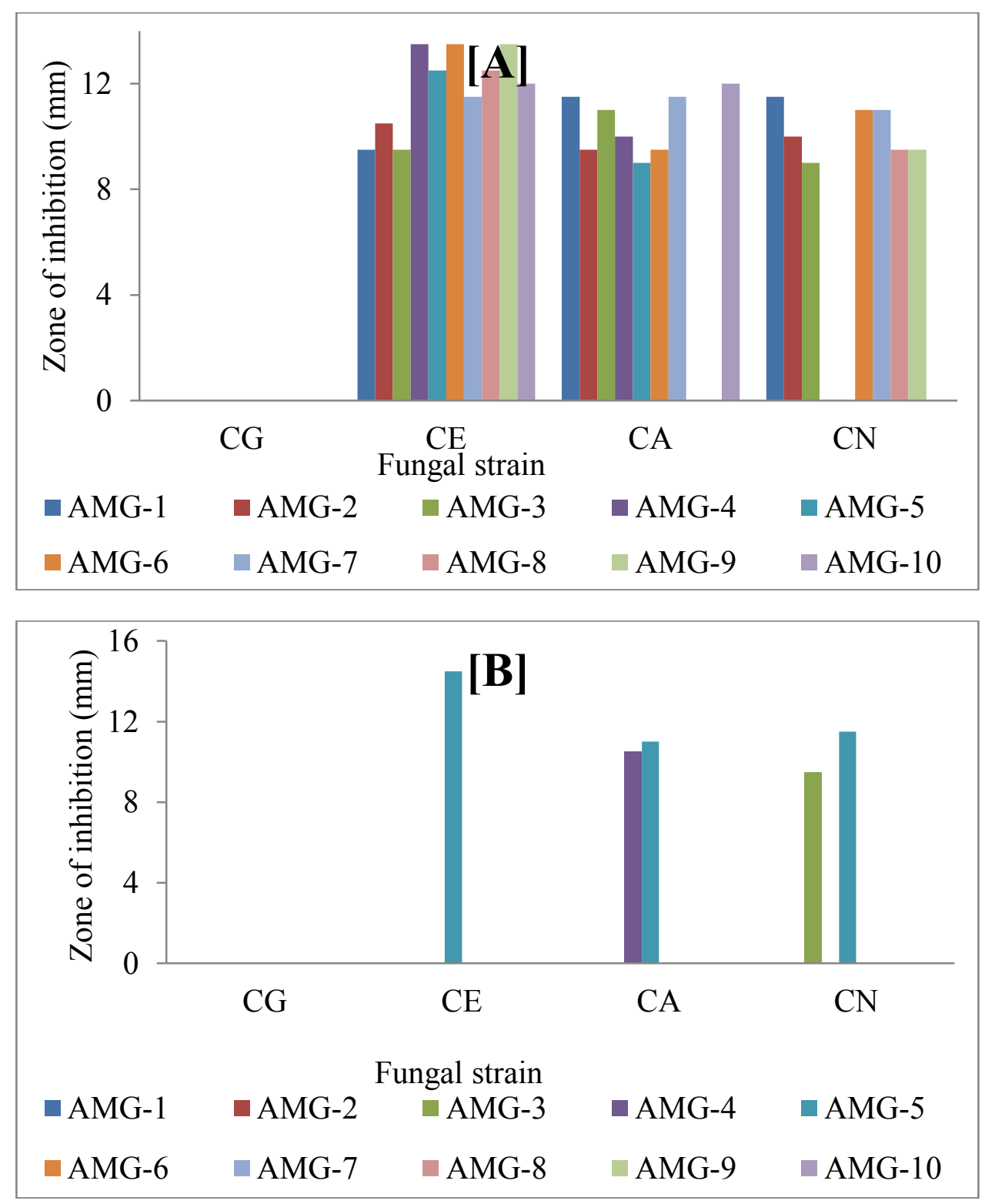

Figure 6: Antifungal activity of compounds AMG-1 to AMG-10 in DMF

\section{References}

[1] A. Kumar, S. Sinha and M. S. Chauhan, Synthesis of novel antimyco-bacterial combinatorial libraries of structurally diverse substituted pyrimidines by three-component solid phase reactions, Bioorg. Med. Chem. Lett. 12 (2002) 667-670.

[2] P. G. Baraldi, M. G. Pavani, M. Nunez, P. Brigidi, B. Vitali, R. Gambari and R. Romagnoli, Antimicrobial and antitumor activity of $N$-heteroimine-1,2,3-dithiazoles and their transformation in triazolo-, imidazo- and pyrazolopyrimidines, Bioorg. Med. Chem. 10 (2002) 449-456.

[3] M. N. Nasr and M. M. Gineinah, Pyrido _2,3-d_pyrimidines and pyrimido _5',4':5,6_pyrido 2,3-d_ pyrimidines as new antiviral agents: Synthesis and biological activity, Arch. Pharm. 335 (2002) 289-295.

[4] S. M. Sondhi, M. Johar, S. Rajvanshi, S. G. Dastidar, R. Shukla, R. Raghubir and J. W. Lown, Anticancer, anti-inflammatory and analgesic activity evaluation of heterocyclic compounds synthesized by the reaction of 4-isothiocyanato-4-methylpentan-2-one with substituted $o$ phenylenediamines, $o$-diaminopyridine and (un)substituted $o$-diaminopyrimidines, Aust. $J$. Chem.54 (2001) 69-74. 
[5] A. Gangjee, A. Vidwans, E. Elzein, J. J. Mc Guire, S. F. Queener and R. L. Kisliuk, Synthesis, antifolate and antitumor activities of classical and nonclassical 2-amino-4-oxo-5substituted--pyrrolo_2,3-d_pyrimidines J. Med. Chem. 44 (2001) 1993-2003.

[6] N. Kumar, G. Singh and A. K. Yadav, Synthesis of some new pyrido_2,3-d_pyrimidines and their ribofuranosides as possible antimicrobial agents, Heteroat. Chem. 12 (2001) 52-56.

[7] G. Mangalagiu, M. Ungureanu, G. Grosu, I. Mangalagiu and M. Petrovanu, New pyrrolopyrimidine derivatives with antifungal or antibacterial properties, Ann. Pharm. Fr. 59 (2001) $139-140$

[8] J. Griffon, J. A. Montgomery and J. A. Secrist, Synthesis and antiproliferative activity of some 4'-C-Hydroxymethyl-_-and -_-D-arabino-pentofuranosyl pyrimidine nucleosides, Nucleosides Nucleotides 20 (2001) 649-652.)

[9] C. Perez, M. Paul, P. Bazerque, An antibiotic assay by the agar well diffusion method, Acta Biol. Med. Exp., 15 (1990) 113-115 